DOI: 10.33727/JRISS.2021.2.19:175-184

\title{
Similarities and differences between the evolutions of the average wheat productions in Romania, South-West Oltenia and Dolj. ARMA models
}

\author{
Marian Zaharia \\ Association for Democracy, Education, Respect, Targu-Jiu, Romania \\ E-mail: marianzahectareria53@gmail.com
}

\begin{abstract}
The evolutions of crop productions are influenced by a series of both deterministic and stochastic factors, so the data series of these evolutions are variable with significant random components. Starting from this consideration, the paper comparatively analyzes the evolutions of the average annual wheat production per hectare at the level of Romania and the South-West Oltenia development region, as well as at the level of Dolj county, component of this region. The main objective is to identify and analyze trend components, based on regression models, as well as random components, based on autoregressive and moving average (ARMA) models in order to identify similarities and differences between the evolutions of average wheat production per hectare in the last two decades. . The conclusion is that, although the evolution trends are similar, the random components highlight differences between the evolutions registered in Romania and in the South-West Oltenia region, which highlights the significant impact of specific random factors.
\end{abstract}

Keywords: crop production, wheat, regression, ARMA

\section{Introduction}

At regional level and not only, the evolution of crop production, implicitly of wheat production is determined by deterministic variables in the form of predictive factors of production, including the development of the material base and technical progress in agriculture [1], regional particularities [2 ], as well as by random factors including climate, and its changes [3], water quality [4], which, although overlapping in a predictable trend, give the data production volume data series the characteristic of random variables.

On the other hectarend, if we take into account the phenomena of soil erosion, water pollution [5] and the consequences of poor waste management [6] we hectareve the image of a process thectaret can no longer be analyzed only by deterministic methods and models.

Starting from these considerations, the paper comparatively analyzes the evolutions of the average annual wheat productions per hectare from 1990-2019 at the level of the South-West Oltenia development region, at the level of Dolj county, as well as at the level of Romania. The analysis concerns both the chectareracteristics of the production trends registered in the three entities and the analysis of the random components thectaret chectareracterize the evolutions.

The main objective of the analysis was to highlight the similarities and differences between the evolutions of average wheat production per hectare, registered in the South-West Oltenia 
development region and in Romania, and on the other hectarend, the similarities and differences between the evolutions of average wheat productions. per hectare registered in Dolj county compared to the South-West Oltenia region, a region of which Dolj county is part.

After presenting the methodologies used for the analysis of trend components and random components, the chectarepter of results and discussions is structured in two sections. The first section analyzes, based on the regression models, the chectareracteristics of the evolution trends of the average wheat productions per hectare, and the second one, based on the autoregressive and mobile average models, analyzes the chectareracteristics of the random components of the respective productions evolutions.

\section{Data series and methodology}

The main data source was the NIS database, respectively Average production per hectare, for the main crops, by forms of ownership, macroregions, development regions and counties [7].

The analysis included the time series corresponding to the average annual wheat productions per hectare in Romania, the South-West Oltenia development region and Dolj county (Table 1), in the period 1990-2019.

Table 1. The variables used to analyze the evolutions of average wheat production per hectare

\begin{tabular}{clr} 
Indicator & \multicolumn{1}{c}{ Significance } & Units \\
\hline PROM & Average wheat production per hectare, in Romania & Kg per ha \\
PSVO & Average wheat production per hectare in the South-West Oltenia region & Kg per ha \\
PDOLJ & Average wheat production per hectare in Dolj County & Kg per ha
\end{tabular}

The first part of the paper aimed at determining and analyzing the time evolution characteristics of average annual wheat production per hectare in Dolj County, South-West Oltenia development region, compared to that recorded in Romania, in the period 1990-2019, and identifying the characteristics of their trends starting from shape models:

$$
Y=f(t)+\varepsilon, \quad t=\overline{0,29}, \quad t_{1990}=0
$$

where $f(t)$ is a polynomial function, and $\varepsilon$ is a residual variable.

The ANOVA methodology and the $\mathrm{F}$ test were used to test the statistical significance of the model $f(t)$ with the null hypothesis: the model is not statistically significant $\left(\mathrm{H}_{0_{-}}\right)$, and its quality assessment was assessed by the value of the coefficient of determination $\mathrm{R}^{2}$. The condition for accepting the null hypothesis $\mathrm{H}_{0} 1$ is:

$$
F_{\text {statistic }}<F_{\alpha, k, n-k-1} \quad \vee \quad \text { Sig.F }>\alpha
$$

The values of the model $f(t)$ parameters were statistically tested with the $t$ test (Student), with the null hypothesis: the value is not statistically significant, it does not differ significantly from zero $\left(\mathrm{H}_{0_{-} 2}\right)$. The condition for accepting the null hypothesis $\mathrm{H}_{0 \_} 2$ is:

$$
t_{\text {statistic }} \in\left(-t_{\frac{\alpha}{2}, n-1}, t_{\frac{\alpha}{2}, n-1}\right) \vee \quad \operatorname{Prob}>\alpha
$$

The JB test was used to test the normality of the variable distributions [8], the test statistic being:

$$
J B=n\left[\frac{S^{2}}{6}+\frac{(K-3)^{2}}{24}\right]
$$


where $\mathrm{S}$ is skewness value and iar $\mathrm{K}$ is kurtosis value.

The null hypothesis of the JB test is: the variable has a normal distribution $\left(\mathrm{H}_{0_{3} 3}\right)$, $v \sim N\left(0, \sigma_{v}^{2}\right), \quad(J B=0, S=0 \wedge K=3)$, the condition of acceptance being:

$$
J B<\chi_{\alpha ; 2}^{2} \vee \operatorname{Prob} \cdot \chi^{2}>\alpha
$$

The ARCH (Autoregressive Conditional Heteroskedasticity Test) and the White (White Heteroskedasticity Test) were used for heteroskedasticity testing. The null hypothesis of the ARCH test is: there is no ARCH up to order 1 in the residuals $\left(\mathrm{H}_{0_{-}}\right)$, and the null hypothesis of the White test is: no heteroskedasticity $\left(\mathrm{H}_{0 \_} 5\right)$. For both tests, the statistic is: $L M=n \cdot R^{2}$, where $\mathrm{n}$ is the number of observations and $\mathrm{R}^{2}$ is the coefficient of determination of their specific auxiliary models. The condition for accepting the null hypothesis is:

$$
L M<\chi_{\alpha, k}^{2} \quad \vee \quad \operatorname{Prob} \cdot \chi^{2}>\alpha
$$

where $\mathrm{k}$ is the number of exogenous variables of the respective auxiliary models

Autocorrelation of residual variable values was performed with the Durbin-Watson Test, whose statistics are:

$$
D W=\frac{\sum_{t=2}^{n}\left(e_{t}-e_{t-1}\right)^{2}}{\sum_{t=1}^{n} e_{t}^{2}}
$$

The null hypothesis of the test is: the residual variable is not auto correlated $\left(\mathrm{H}_{0 \_} 6\right)$, the condition of its acceptance being:

$$
D W \in\left[d_{s}(n, k), 4-d_{s}(n, k)\right]
$$

In (8), $d_{s}(n, k)$ is the tabulated value from which begins the acceptance interval of the null hypothesis corresponding to a series of $\mathrm{n}$ observations and $\mathrm{k}$ exogenous variables.

The second part of the paper presents an analysis of the evolution over time of the average annual wheat production per hectare of the three entities using the autoregressive models AR (p) and moving average MA (q), of the form [9]:

$$
y_{t}=\phi_{0}+\sum_{i=1}^{p} \phi_{i} y_{t-i}+\varepsilon_{t}+\sum_{i=1}^{q} \theta_{i} \varepsilon_{t-i}
$$

were $\phi_{i}$ and $\theta_{i}$ are the parameters of the model, and $\varepsilon_{t} \sim N\left(0, \sigma_{\varepsilon}^{2}\right)$ stationary series, $M\left(\varepsilon_{t}\right)=0$, $M\left(\varepsilon_{t}^{2}\right)=\sigma^{2}$ and $\operatorname{cov}\left(\varepsilon_{t}, \varepsilon_{i}\right)=0 \forall t \neq i$.

The Dickey-Fuller Augumented test [10] was used to test the stationarity of the data series of the average annual wheat production per hectare [10], with the null hypothesis: the data series has a unit root (H0_7). The condition for accepting the null hypothesis H0_7 is:

$$
t_{\text {statistic }}<\left|t_{\frac{\alpha}{2}, \text { lag-1 } 1}\right| \vee \quad \text { Prob }>\alpha
$$

After verifying the stationarity and eliminating the seasonal component, the determination of the parameter values of the models (9) was performed with least squeare method. For testing the validity of the obtained models, tests $\mathrm{F}$ and $\mathrm{t}$ were also used, with the conditions for accepting null hypotheses (2) 
and (3), and for testing the values of the residual variables tests $\mathrm{JB}, \mathrm{ARCH}$, White and DW, the conditions for accepting null hypotheses being (3-6) and (8).

The significance threshold used is $\alpha=0.05$, corresponding to the $95 \%$ confidence level.

\section{Results and discussions}

The evolutions of the average annual wheat productions per hectare in the Romanian agriculture, in the absence of an efficient irrigation system, continue to be strongly influenced by the climatic evolutions, and first of all by the periods and quantities of precipitations from each year, so that the corresponding data series have the appearance of relatively random series.

\subsection{Similarities and differences of evolutions over time}

Although, at first sight, the evolutions of the average wheat productions per hectare registered in the period 1990-2019, both at the level of Romania and at the level of the South-West Oltenia development region and at the level of Dolj county (Figure 1) are similar, however, certain peculiarities can be highlighted during the analyzed period.

In the period 1990-2003, although the general trend of the average annual wheat production per hectare was a downward one, positive and negative fluctuations of large and very large amplitudes overlapped, recorded in the evolution of the three time series, both simultaneously., as well as at different times. Thus, while a minimum first of the average wheat production per hectare, at the level of Romania was registered in $1992,2329 \mathrm{Kg}$ (67.85\% compared to 1990), the first minimum values, at the level of the South-West Oltenia region ( $1981 \mathrm{Kg}$ ) and Dolj County $(1572 \mathrm{Kg})$, were registered in 1993 (51.99\% and 38.78\% compared to 1990). On the other hand, the first positive jump is registered in the South-West Oltenia region $(3303 \mathrm{Kg}$ ) and in Dolj county $(3105 \mathrm{Kg})$, in 1994, one year before the first maximum of the average wheat production per hectare, registered at the level of Romania $(3090 \mathrm{Kg}$, $95.52 \%$ compared to 1990$)$.

The lowest level of average wheat production per hectare is also recorded at different times. In the South-West Oltenia region and in Dolj county, the absolute minimums of the entire analyzed period were registered in 2002, when the production level was only $25.73 \%$ and $6.43 \%$ respectively compared to the level registered in 1990. At the level of Romania, the absolute minimum level of wheat production per hectare $(1429 \mathrm{Kg})$ was recorded in 2003 , year in which wheat production per hectare had increased by 14.10 percentage points, in the South-West Oltenia region, and by 28.94 percentage points, in Dolj county .

After 2003, the average wheat production per hectare is on an upward trend in all three entities analyzed, so that in 2019 , there were average productions of $4749 \mathrm{Kg}$ in Romania (48.80\% higher than in 1990), of $4748 \mathrm{Kg}$, at the level of the South-West Oltenia region (by $28.71 \%$ higher than in 1990) and of $4491 \mathrm{Kg}$, at the level of Dolj county (10.62\% higher than in 1990).

This increase was not linear, but with significant oscillations. Thus, in 2007, in all three entities, there is a significant new decrease, its level, compared to 1990 , was $47.64 \%$ in Romania, $21.39 \%$ in the SouthWest Oltenia region and only $16.50 \%$, in Dolj County.

Although after 2007 the amplitudes of positive and negative fluctuations decrease, there are still differences between the moments of their occurrence. Thus, after a maximum of wheat production per hectare registered in 2008, in Romania and Dolj county new minimum values are registered $(74.84 \%$ and $63.69 \%$ respectively compared to 1990), while in the South-West Oltenia region, the minimum value $(2478 \mathrm{Kg}, 67.17 \%$ compared to 1990$)$ is registered in 2010. 


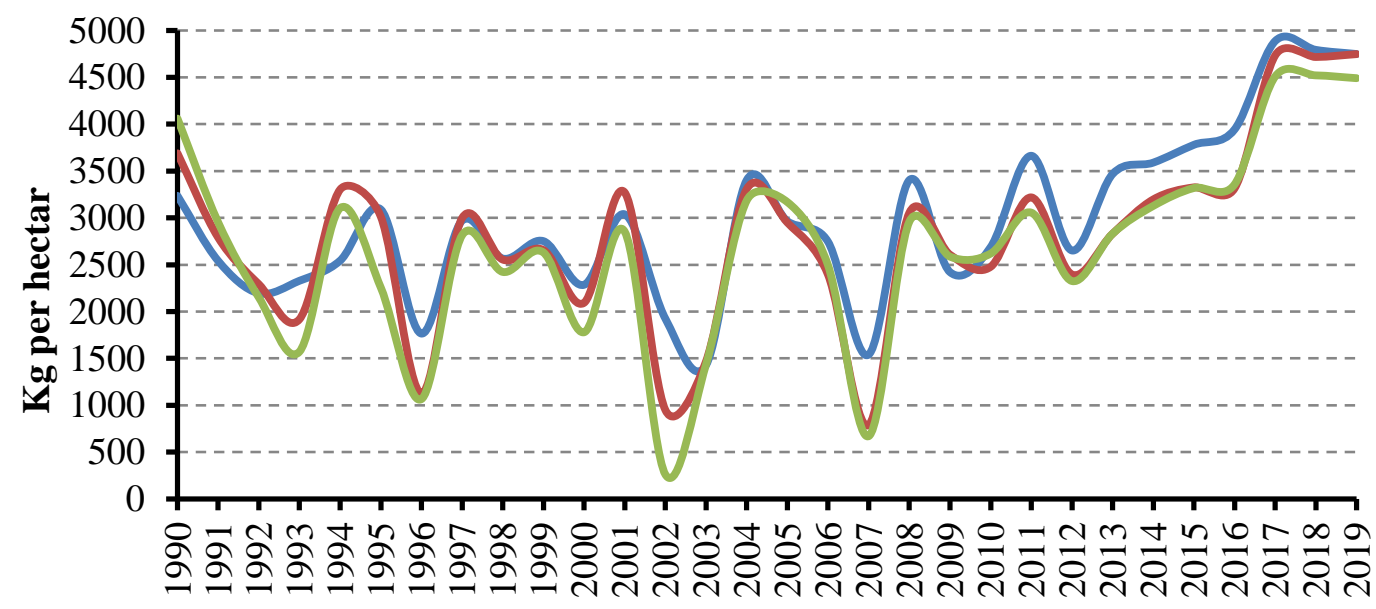

\section{-România —South-West Oltenia —Dolj}

Figure 1 Evolutions of average wheat production per hectare recorded in the period 1990-2019, in

Romania, South-West Oltenia development region and Dolj county

There are also differences between the times when maximum values are recorded. Thus, while in 2017 there are maximum values of average wheat production per hectare, in Romania, of $4888 \mathrm{Kg}$ (51.10\% more than in 1990), and $4735 \mathrm{Kg}$, in the South-West region. Oltenia (with $28.35 \%$ more than in 1990), at the level of Dolj county, the maximum production $(4521 \mathrm{Kg}$, with $11.35 \%$ more than in 1990) was registered in 2018.

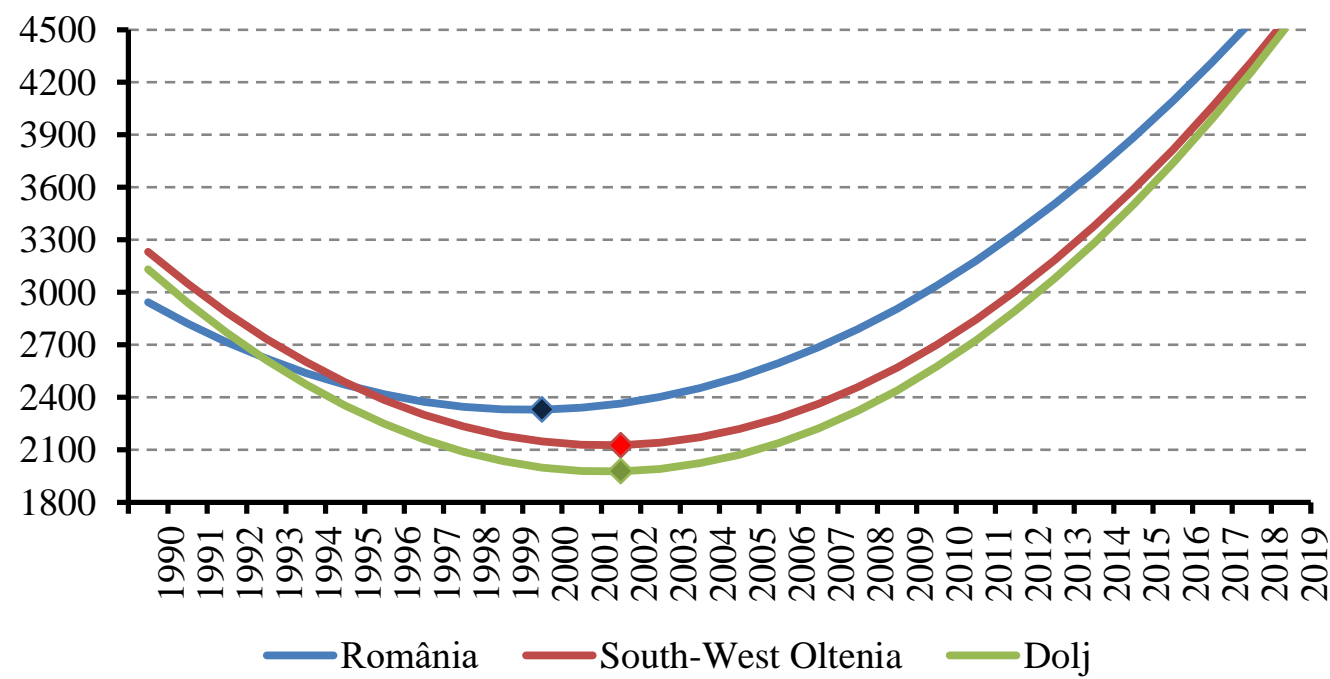

Figure 2 Trends in the evolution of average wheat production per hectare registered in Romania, South-West Oltenia development region and Dolj county, in the period 1990-2019

Significant differences between the wheat production per hectare registered in the three entities are also highlighted in terms of when its volume begins to exceed the value recorded in 1990. While, at the level of Romania, this fact occurs since 2013, in the case of the South-West Oltenia region and Dolj County, this level starts to be exceeded only starting with 2017. 
A common feature of the evolutions over time of the average annual wheat production per hectare in Romania, the South-West Oltenia development region and Dolj County is the fact that these trends, corresponding to the periods 1990-2019 (figure 2), are polynomial functions of the form:

$$
Y(t)=a+b \cdot t+c \cdot t^{2}, \quad a, b, c \in R, \quad t_{1990}=0
$$

The values of the model parameters, of the coefficients of determination as well as of the corresponding $\mathrm{F}$ test are presented in table 2. Given that for all three models the values of the F statistic are higher than the critical value $\left(F_{c}=F_{0.05,2,27}=3.3541\right.$ ), it follows that the null hypothesis $\mathrm{H}_{0_{-} 1}$ is rejected and, consequently, they are statistically significant. More taking into account the fact that Sig. $F<0.01$, the confidence factor is $99 \%$.

Table 2 Parameter values and model test results

\begin{tabular}{|c|c|c|c|c|c|c|c|c|c|c|}
\hline \multicolumn{3}{|c|}{ Model } & & \multicolumn{3}{|c|}{ Coefficients } & \multicolumn{4}{|c|}{ Residual Diagnostics } \\
\hline Indent. & $\mathrm{R}^{2}$ & Sig.F & & Value & t-Stat. & Prob. & $\begin{array}{c}\text { JB } \\
\left(\text { Prob. } \chi^{2}\right)\end{array}$ & $\begin{array}{l}\mathrm{ARCH} \\
\left(\text { Prob. } \chi^{2}\right)\end{array}$ & $\begin{array}{l}\text { White } \\
\left(\text { Prob. } \chi^{2}\right)\end{array}$ & DW \\
\hline \multirow{3}{*}{ PROM } & \multirow{3}{*}{0.658} & \multirow{3}{*}{0.000} & $\mathrm{a}$ & 2943.796 & 10.647 & 0.000 & \multirow{3}{*}{$\begin{array}{c}0.801 \\
(0.669)\end{array}$} & \multirow{3}{*}{$\begin{array}{l}0.6159 \\
(0.439)\end{array}$} & \multirow{3}{*}{$\begin{array}{c}2.054 \\
(0.117)\end{array}$} & \multirow{3}{*}{2.492} \\
\hline & & & $\mathrm{b}$ & -127.414 & -2.887 & 0.008 & & & & \\
\hline & & & $\mathrm{c}$ & 6.600841 & 4.488 & 0.000 & & & & \\
\hline \multirow{3}{*}{ PSVO } & \multirow{3}{*}{0.499} & \multirow{3}{*}{0.000} & $\mathrm{a}$ & 3232.424 & 8.762 & 0.000 & \multirow{3}{*}{$\begin{array}{c}1.179 \\
(0.554)\end{array}$} & \multirow{3}{*}{$\begin{array}{c}0.4504 \\
(0.771)\end{array}$} & \multirow{3}{*}{$\begin{array}{c}1,379 \\
(0.269)\end{array}$} & \multirow{3}{*}{2.313} \\
\hline & & & $\mathrm{b}$ & -190.335 & -3.232 & 0.003 & & & & \\
\hline & & & $\mathrm{c}$ & 8.18379 & 4.171 & 0.000 & & & & \\
\hline \multirow{3}{*}{ PDOLJ } & \multirow{3}{*}{0.499} & \multirow{3}{*}{0.000} & $\mathrm{a}$ & 3132.506 & 8.021 & 0.000 & \multirow{3}{*}{$\begin{array}{c}1.748 \\
(0.417)\end{array}$} & \multirow{3}{*}{$\begin{array}{l}0.0186 \\
(0.893)\end{array}$} & \multirow{3}{*}{$\begin{array}{c}1,888 \\
(0.144)\end{array}$} & \multirow{3}{*}{2.041} \\
\hline & & & $\mathrm{b}$ & -198.748 & -3.188 & 0.003 & & & & \\
\hline & & & $\mathrm{c}$ & 8.54041 & 4.112 & 0.000 & & & & \\
\hline
\end{tabular}

JB: Jarque-Bera Normality Test

ARCH: Autoregressive Conditional Heteroskedasticity Test

White: White Heteroscedasticity Test

DW: Durbin-Watson statistic

Source: own determination

The coefficients of the resulting models are also statistically significant. This attribute results from the fact that the absolute values of $t$-State are higher than the critical value $t_{c}=2,048407$ ( respectively, Prob $<0.05$ ), which leads to the rejection of the null hypothesis $\mathrm{H}_{0 \_}$.

Residual diagnostics of the three models highlight their normality, the results of the Jarque-Bera test leading to the acceptance of the null hypothesis $\mathrm{H}_{0 \_}$(Prob.F> 0.05). Also, the $\mathrm{ARCH}$ and White tests lead to the acceptance of the null conclusions $\mathrm{H}_{0_{-} 4}$ (there is no $\mathrm{ARCH}$ up to order 1 in the residuals) and $\mathrm{H}_{0 \_} 5$ (of no heteroskedasticity).

Regarding the autocorrelation of the errors, considering that $d_{s}(30,1)=1.489$ it results that the interval of acceptance of the null hypothesis H0_6 (no autocorrelation) is [1,489,2,511]. Consequently, in none of the three models are the values of the residual variables auto correlated

In conclusion, the trends of wheat production per hectare registered in Dolj County, South-West Oltenia development region, as well as in Romania, in the period 1990-2019 were of parabolic type, with minimums recorded in 2000, in Romania, and in 2002, in the case of Dolj County and the SouthWest Oltenia region. 


\subsection{ARMA models of random components}

Starting from the evolutions of the average wheat production per hectare in the South-West Oltenia development region and Dolj county, compared to the average wheat production per hectare registered in Romania, highlighted by the PSVO, PDOLJ and PROM data series and using Hodrick-Prescott Filter, the data series corresponding to the trend components and the random components of the initial data series were generated.
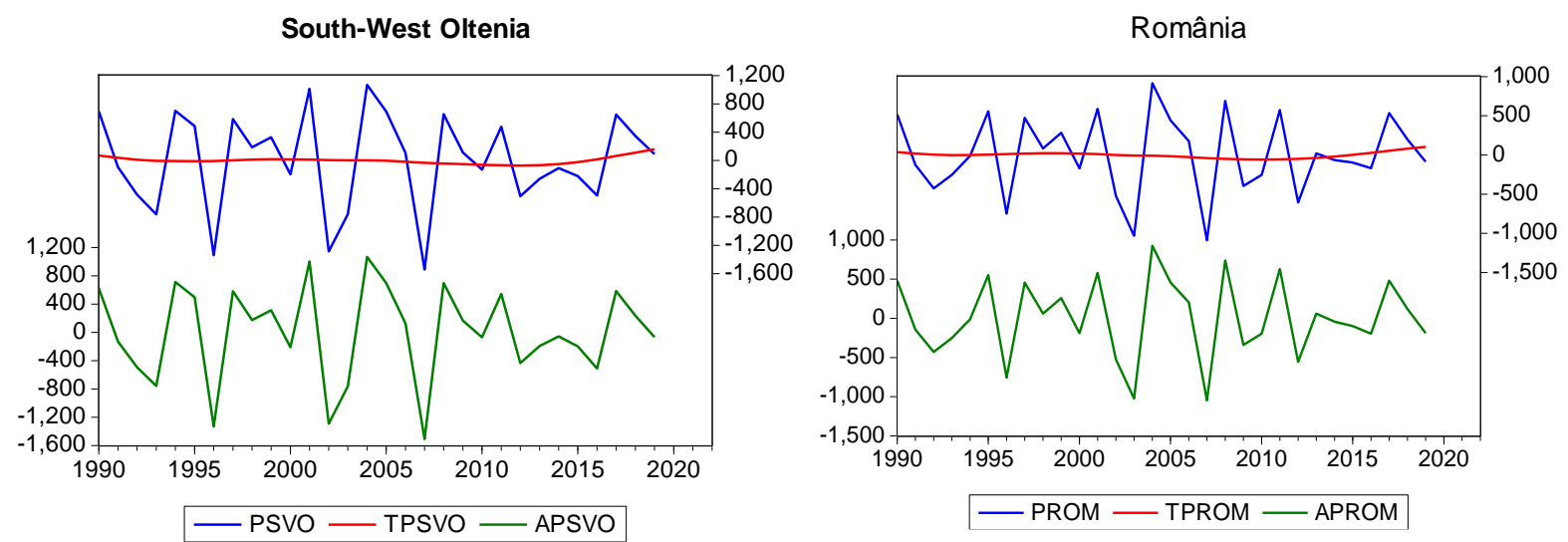

Figure 3 Generation with Hodrick-Prescott Filter of the trend and random components of the evolution of the average wheat production per hectare in Romania and the South-West Oltenia region

Developments of the trend component (TPSVO) and the random component (APSOV) of the average annual wheat production per hectare in the South-West Oltenia development region (PSVO), as well as of the trend component (TPROM) and of the random component (APROM) corresponding to the production annual averages of wheat per hectare in Romania (PROM) are presented in figure 3.

Table 3 The results of Augumented Dickey-Fuller Unit Root Test for PROM, SVO and DOLJ series

\begin{tabular}{|c|c|c|c|c|c|c|}
\hline \multirow{2}{*}{\multicolumn{3}{|c|}{ Null Hypothesis: series has a unit root }} & \multicolumn{2}{|c|}{ Level } & \multicolumn{2}{|c|}{$1^{\text {st }}$ difference } \\
\hline & & & \multirow{2}{*}{ 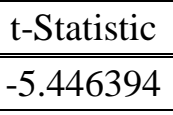 } & \multirow{2}{*}{$\begin{array}{c}\text { Prob. } \\
0.0001\end{array}$} & \multirow{2}{*}{$\begin{array}{l}\text { t-Statistic } \\
-5.498474\end{array}$} & \multirow{2}{*}{$\begin{array}{c}\text { Prob. } \\
0.0002\end{array}$} \\
\hline \multirow{3}{*}{ APSVO } & \multicolumn{2}{|c|}{ Augmented Dickey-Fuller test statistic } & & & & \\
\hline & Test critical values: & $1 \%$ level & -3.699871 & & -3.752946 & \\
\hline & & $5 \%$ level & -2.976263 & & -2.998064 & \\
\hline \multirow{3}{*}{ APDOLJ } & Augmented Dickey & t statistic & -5.208871 & 0.0002 & -5.483281 & 0.0002 \\
\hline & Test critical values: & $1 \%$ level & -3.699871 & & -3.752946 & \\
\hline & & $5 \%$ level & -2.976263 & & -2.998064 & \\
\hline \multirow{3}{*}{ APROM } & Augmented Dicke & st statistic & -6.021059 & 0.0000 & -5.025891 & 0.0005 \\
\hline & Test critical values: & $1 \%$ level & -3.689194 & & -3.752946 & \\
\hline & & $5 \%$ level & -2.971853 & & -2.998064 & \\
\hline
\end{tabular}

Source:own calculus

The verification of the stationary series of the random components of the average wheat production per hectare in the South-West Oltenia region (APSVO), Dolj county (APDOLJ) and in Romania (APROM) was performed with Augmented Dickey-Fuller Unit Root Test (Table 3). Considering that the t-statistical values of Augmented Dickey-Fuller statistical test are lower than both Critical Test values 5\% and 1\% level, as well as the fact that Prob. $<\alpha=0.05$, it follows that all three random data series are stationary. 
From the analysis of the possible evolution models of the random components of the analyzed data series, and taking into account the values of Akaike info criterion and Schwarz criterion, three $\operatorname{ARMA}(n, m)$ models were obtained.

An ARMA(3.2) model was obtained for the APSVO random component. Given that $\operatorname{Prob}($ F- statistic $)=0.019711<\alpha=0.05$ (Table 4) shows that the model is statistically significant (valid). Also, the coefficients of the factorial variables $\mathrm{AR}(3)$ and $\mathrm{MA}(2)$ are statistically significant for the chosen $95 \%$ confidence level. $(\alpha=0.05)$.

Table 4 Testing the parameters of the ARMA model (3.2) for the APSVO series

\begin{tabular}{|c|c|c|c|c|}
\hline Variable & Coefficient & Std. Error & t-Statistic & Prob. \\
\hline $\mathrm{C}$ & -11.92100 & 20.78193 & -0.573623 & 0.5716 \\
\hline $\operatorname{AR}(3)$ & -0.375371 & 0.178974 & -2.097351 & 0.0467 \\
\hline $\operatorname{MA}(2)$ & -0.952358 & 0.039972 & -23.82550 & 0.0000 \\
\hline F-statistic & 4.640983 & \multicolumn{2}{|c|}{ Akaike info criterion } & 15.79754 \\
\hline Prob(F-statistic) & 0.019771 & \multicolumn{2}{|c|}{ Schwarz criterion } & 15.94153 \\
\hline Inverted AR Roots & $0.36-0.62 \mathrm{i}$ & $0.36+0.62 \mathrm{i}$ & -0.72 & \\
\hline Inverted MA Roots & 0.98 & \multicolumn{2}{|c|}{-0.98} & \\
\hline
\end{tabular}

Dependent Variable: APSVO, Method: Least Square, Sample (ajusted) 1993-2019, Included observations: 27 after adjusting, Convergence achieved after 11 iterations

Source: own determination

In the case of the random component APDOLJ, of the data series of the average wheat production per hectare in Dolj county, an $\operatorname{ARMA}(3,2)$ model was also obtained, And in this case, given that $\operatorname{Prob}(\mathrm{F}$ - statistic $)=0.007787<\alpha=0.05$ (Table 5) shows that the model is statistically significant (valid). Also, the coefficients of the factorial variables $\mathrm{AR}(3)$ and $\mathrm{MA}(2)$ are statistically significant for the chosen $95 \%$ confidence level.

Table 5 Testing the parameters of the ARMA(3.2) model for the APDOLJ series Variable Coefficient Std. Error t-Statistic Prob.

\begin{tabular}{rrrrr}
\hline \hline $\mathrm{C}$ & -7.623908 & 18.99025 & -0.401464 & 0.6916 \\
$\mathrm{AR}(3)$ & -0.437641 & 0.176286 & -2.482569 & 0.0204 \\
$\mathrm{MA}(2)$ & -0.963644 & 0.041942 & -22.97559 & 0.0000 \\
\hline \hline F-statistic & 5.984661 & Akaike info criterion & 15.82185 \\
Prob(F-statistic) & 0.007787 & Schwarz criterion & 15.96583 \\
\hline \hline Inverted AR Roots & $0.38+0.66 \mathrm{i}$ & \multirow{2}{*}{$0.38-.66 \mathrm{i}$} & -0.76 & \\
Inverted MA Roots & 0.98 & & -0.98 & \\
\hline \hline
\end{tabular}

Dependent Variable: APDOLJ, Method: Least Square, Sample (ajusted) 1993-2019, Included observations: 27 after adjusting, Convergence achieved after 9 iterations Source: own determination

For the third random variable APROM, component of the data series of average annual production per hectare, an ARMA(7.2) model was obtained in Romania. Also for this model, given that $\operatorname{Prob}(\mathrm{F}$ - statistic $)=0.030945<\alpha=0.05$ (Table 6) shows that it is statistically significant. Also, taking 
into account that the parameter values Prob. $<\alpha=0.05$, in the case of both factor variables, it follows that the values of their coefficients are statistically significant for the significance threshold $\alpha=0.05$.

Table 6 Testing the parameters of the ARMA(7.2) model for the APROM series

\begin{tabular}{cccrr} 
Variable & Coefficient & Std. Error & t-Statistic & Prob. \\
\hline \hline C & -38.75561 & 53.33864 & -0.726595 & 0.4759 \\
$\mathrm{AR}(7)$ & 0.460777 & 0.177720 & 2.592710 & 0.0174 \\
$\mathrm{MA}(2)$ & -0.935253 & 0.059508 & -15.71643 & 0.0000 \\
\hline F-statistic & 4.156010 & Akaike info criterion & 15.22763 \\
Prob(F-statistic) & 0.030945 & Schwarz criterion & 15.37574 \\
\hline \hline Inverted AR Roots & 0.90 & $0.56-0.70 \mathrm{i}$ & $0.56+0.70 \mathrm{i}$ & $-0.20-0.87 \mathrm{i}$ \\
& $-0.20+.87 \mathrm{i}$ & $-0.81+.39 \mathrm{i}$ & $-0.81-.39 \mathrm{i}$ & \\
Inverted MA Roots & 0.97 & -0.97 & &
\end{tabular}

Dependent Variable: APROM, Method: Least Square, Sample (ajusted) 1993-2019, Included observations: 23 after adjusting, Convergence achieved after 14 iterations

Source: own determination

The models obtained, corresponding to the three random components, are:

$$
\begin{array}{r}
\text { APSVO }=-11.9210+[\operatorname{AR}(3)=-0.375371, \mathrm{MA}(2)=-0.952358, \\
\text { BACKCAST }=1993, \operatorname{ESTSMPL}=" 19932019 "] \\
\text { APDOLJ }=-7.623908+[\operatorname{AR}(3)=-0.437641, \mathrm{MA}(2)=-0.963644, \\
\text { BACKCAST }=1993, \mathrm{ESTSMPL}=" 19932019 "] \\
\text { APROM }=-38.75561+[\mathrm{AR}(7)=0.460777, \mathrm{MA}(2)=-0.935253, \\
\mathrm{BACKCAST}=1997, \mathrm{ESTSMPL}=" 19972019 "]
\end{array}
$$

The analysis of the obtained models shows a rather high similarity between the APSVO and APDOLJ springs. Both are $\operatorname{ARMA}(3,2)$ models, and the differences between the values of the $\operatorname{AR}(3)$ coefficients being 0.06227 units, and between the MA(2) coefficients being only 0.011286 units (approximately $1.2 \%$ ).

In contrast, the APROM model is different being an $\operatorname{ARMA}(7,2)$ model. At the same time there is a similarity between it and the other two models in terms of the moving average component MA(2), the value of its coefficient differing by 0.028391 units from that corresponding to the APDOLJ model, respectively by 0.017105 units compared to the coefficient MA(2) corresponding to the APSVO model.

\section{Conclusions}

The comparative analysis of the evolutions of the average annual wheat productions per hectare at the level of the developed South-West Oltenia region, Dolj county, as well as at the level of Romania, in the period 1990-2019 highlights both similarities and differences.

The main similarity between these evolutions is the parabolic shape of the evolution trend, as well as the fact that after 2010 they tend to become convergent. The difference consists in the fact that, in the case of Romania, the minimum value of the trend of the evolution of the average wheat production per hectare was registered in 2000, and in the South-West Oltenia region and Dolj county, in 2002.

From the point of view of the random component, there are significant similarities between the South-West Oltenia region and Dolj County, a component county of this region. This similarity highlights that the average annual production of wheat per hectare in Dolj County was defining for the 
average production in the South-West Oltenia region, the influences of the evolutions of the average annual wheat production per hectare being small.

On the other hand, the differences between the random component model corresponding to the evolution of the average annual wheat production per hectare, in Romania, compared to those corresponding to the South-West Oltenia region and Dolj County show influences of local and regional factors that occurred during review period.

\section{References}

[1] Constantin, Florentina and Ciobanu, Laura, (2011), Aspects of Technical Progress in Romanian Agriculture Compared to Some EU Countries, Economia. Seria Management, 14, issue 2, p. 473-483.

[2] Zaharia, M., Gogonea, R-M. and Balacescu, A. (2021)Territorial dimension of wheat production in Romania. MPRA (Munich Personal RePEc Archive). Paper No. 106301, posted 04 Mar 2021

[3] Taylor, C., Cullen, B., D'Occhio, M., Rickards, L. and Eckard, R., (2018), Trends in wheat yields under representative climate futures: Implications for climate adaptation, Agricultural Systems, 164, issue C, p. 1-10.

[4] Andrei, J. V., Bălăcescu, A., Chivu, L., Gogonea, R. M., Patrascu, A., Zaharia, M. (2021).Water productivity, exploitation and footprint tools in understanding environmental policy. Applied Ecology and Environmental Research. 19(3):2541-2564.

[5] Stroia, A., (2006), Environmental Policies Against Water Pollution in Romania, ch. 3 in , Multidimensional Research in Humanistic Sciences (English Version), vol. 1, Editor Lumen.

[6] Gogonea, Rodica-Manuela, Zaharia, Marian, Balacescu, Aniela (2021) Territorial Disparities of the Waste Generation and Resource Productivity in Sustainable Development. ECOFORUM, Volume 10, Issue 2(25), 2021

[7] NIS Tempo online. AGR110A - Average crop production per hectare by main crop, ownership form, macroregions, development regions and counties http://statistici.insse.ro:8077/tempo-online/\#/pages/tables/insse-table

[8] Jarque, C.M., Bera, A.K.(1987). A test for normality of observations and regression residuals. International Statistical Review 1987, 55 (2), 163-172.

[9] Oprescu, Gheorghe. (2007) Dimamică economică stochectarestică. Mecanisme de filtrare și predicție, Editor ASE, București

[10] Popescu, Teodor. (2000). Serii de timp. Aplicații în analiza sistemelor, Editor Tehnică, București 